\title{
ADAPTABILIDADE E ESTABILIDADE DE GENÓTIPOS DE GIRASSOL NOS ESTADOS DO RIO GRANDE DO SUL E PARANÁ
}

\author{
Adaptability and stability of sunflower genotypes from the states of Rio Grande do Sul and Paraná
}

\author{
Anna Karolina Grunvald ${ }^{1}$, Claudio Guilherme Portela de Carvalho ${ }^{2}$, \\ Ana Cláudia Barneche de Oliveira ${ }^{3}$, Carlos Alberto de Bastos Andrade ${ }^{4}$
}

\begin{abstract}
RESUMO
Neste trabalho, objetivou-se estudar a adaptabilidade e estabilidade de genótipos de girassol nos Estados do Rio Grande do Sul e Paraná, quanto a rendimento de grãos e de óleo. Os dados analisados foram obtidos da Rede de Ensaios de Avaliação de Genótipos de Girassol, coordenada pela Embrapa Soja, entre 2003 e 2007. Os ensaios foram conduzidos em delineamento de blocos ao acaso, com quatro repetições. Os métodos usados foram os de Eberhart \& Russel, Lin \& Binns e Annicchiarico. Correlações próximas da unidade, em valores absolutos, foram obtidas entre a média geral dos genótipos e os parâmetros de adaptabilidade dos métodos de Lin \& Binns e Annicchiarico. Contudo, o método de Eberhart \& Russel teve a vantagem de indicar genótipos com adaptação a ambientes específicos. Nesse método, os híbridos Agrobel 959 e Helio 360 e a variedade BRSGira 02 foram considerados ideais, por apresentar bons desempenhos em rendimento de grãos, adaptabilidade geral e boa previsibilidade. Para rendimento de óleo, essas características foram encontradas nos híbridos Agrobel 959 e EXP 1441 e nas variedades BRSGira 01, BRSGira 02 e BRSGira 03.
\end{abstract}

Termos para indexação: Helianthus annuus L., rendimento de grãos, rendimento de óleo.

\section{ABSTRACT}

The objective of this paper was to study the adaptability and stability of sunflower genotypes from the states of Rio Grande do Sul and Paraná, according to their grain and oil yield. The analyzed data were obtained from the Official Sunflower Trials Network, coordinated by Embrapa Soja, from the year 2003 to 2007. The experiment was carried out in randomized block design with four replicates. The Eberhart \& Russel, Lin \& Binns, and Annicchiarico methods were used. Correlations close to the unit in absolute values were obtained between the general average of genotypes and the adaptability parameters of Lin \& Bins and Annicchiarico methods. However, the method of Eberhart \& Russel had the advantage of indicating genotypes with adaptation to specific environments. According to this method, the hybrids Agrobel 959 and Helio 360, and the variety BRSGira 02 were considered ideal, for showing good performance in yield grain, general adaptability and good previsibility. For oil yield, these characteristics were found in the hybrids Agrobel 959 and EXP 1441 as well as in the varieties BRSGira 01, BRSGira 02, and BRSGira 03.

Index terms: Helianthus annuus L., grain yield, oil yield.

\section{(Recebido em 22 de setembro de 2008 e aprovado em 15 de abril de 2009)}

\section{INTRODUÇÃO}

Diante da crescente busca de novas alternativas ao uso do petróleo, o estímulo à produção de biodiesel tem aumentado por se tratar de fonte renovável de energia e por seu uso provocar menos dano ao ambiente (Knothe, 2005). Dentre as matérias-primas existentes para produção de biodiesel no Brasil, o Governo Federal tem indicado o óleo de girassol (Helianthus annuus L.) (Machado, 2008). Isso é em razão de o girassol apresentar alto teor de óleo em suas sementes; boa qualidade do co-produto (torta) obtido pelo processo de extração; boa adaptação a diferentes condições edafo-climáticas; opções práticas para semeadura e colheita; tratos culturais bem definidos em tecnologias geradas e/ou adaptadas pela pesquisa; além de boa alternativa aos sistemas de rotação ou sucessão de culturas, nas regiões produtoras de grãos. Apesar de ser recente, a produção de biodiesel deverá ter, em breve, grande influência na economia do País, pois, de acordo com a legislação vigente, a partir de julho de 2008, será obrigatório adicionar 3\% de biodiesel no diesel de petróleo (Agência Nacional do Petróleo-ANP, 2008). Além do mercado potencial de combustível, o Brasil apresentou déficit na balança comercial de US\$20,8 milhões, em 2007, em razão da importação de óleo, sementes e torta de girassol para alimentação humana (CONAB, 2007). Assim, o

\footnotetext{
${ }^{1}$ Mestre em Genética e Melhoramento. Universidade Estadual de Maringá, Departamento de Agronomia, Av. Colombo, 5790, $87020-900$ Maringá, PR karolgrunvald@hotmail.com

2Doutor em Genética e Melhoramento. Embrapa Soja, C.P. 231 - 86001-970 - Londrina, PR. E-mail: cportela@cnpso.embrapa.br

${ }^{3}$ Doutor em Agronomia. Embrapa Clima Temperado, Caixa Postal 403, CEP 96001-970, Pelotas, RS. E-mail: barneche@cpact.embrapa.br ${ }^{4}$ Doutor em Agronomia. Universidade Estadual de Maringá, Departamento de Agronomia, Av. Colombo, 5790, 87020-900 Maringá, PR. E-mail: cabandrade@uem.br
} 
estímulo à produção de girassol é relevante, pois existe um grande mercado interno.

Em 2007, o girassol foi a quinta oleaginosa em produção de grãos (27,53 milhões de toneladas) e em área cultivada (22,76 milhões de hectare) no mundo, enquanto que no Brasil foi cultivado numa área de quase $100 \mathrm{mil}$ hectares. Dentre os estados brasileiros produtores, incluem-se o Rio Grande do Sul e o Paraná, onde a semeadura feita entre os meses de agosto e outubro, em cultivo antecipado, minimiza os riscos de doenças limitantes e favorece a colheita em épocas de altas temperaturas.

O sucesso do estabelecimento da cultura do girassol no sistema produtivo brasileiro depende, entre outros fatores, não só da época de semeadura, mas também da utilização de genótipos adaptados às regiões de cultivo. No Brasil, desde 1989, a seleção de genótipos, várias empresas, têm sido realizada por meio da Rede de Ensaios de Avaliação de Genótipos de Girassol, coordenada pela Embrapa Soja. O critério de indicação desses genótipos tem tido como base a produtividade média, obtida nos ambientes testadores. Contudo, essa indicação pode prejudicar os cultivares com adaptação a condições específicas. Essa informação, além da identificação de genótipos de comportamento previsível, pode ser obtida por meio do estudo de adaptabilidade e estabilidade dos genótipos. Em girassol, poucos estudos com essa ênfase têm sido realizados (Porto et al., 2007, 2008). Neste trabalho, objetivou-se estudar a adaptabilidade e a estabilidade de genótipos de girassol, nos Estados do Rio Grande do Sul e Paraná, quanto ao rendimento de grãos e óleo, avaliados na Rede de Ensaios de Avaliação de Genótipos de Girassol, entre 2003 e 2007.

\section{MATERIAL E MÉTODOS}

Foram analisados os dados de rendimento de grãos e de óleo $\left(\mathrm{kg} \mathrm{ha}^{-1}\right)$ obtidos da Rede de Ensaios de Avaliação de Genótipos de Girassol, coordenada pela Embrapa Soja, a qual conta com a participação de diversas instituições públicas e privadas. Esses ensaios foram conduzidos entre 2003 e 2007, em diversos locais, dos Estados do Rio Grande do Sul (RS) e do Paraná (PR) (Tabela 1).

Os ensaios foram semeados no período de agosto a outubro, utilizando-se o delineamento experimental de blocos completos casualizados, com quatro repetições. Cada parcela foi constituída por quatro linhas de 6,0 m, espaçadas de 0,7 a $0,9 \mathrm{~m}$. As duas linhas externas de cada parcela (bordaduras) foram descartadas, assim como $0,5 \mathrm{~m}$ de cada extremidade das duas linhas centrais, o que representou uma área útil de 7,0 a 9,0 m².

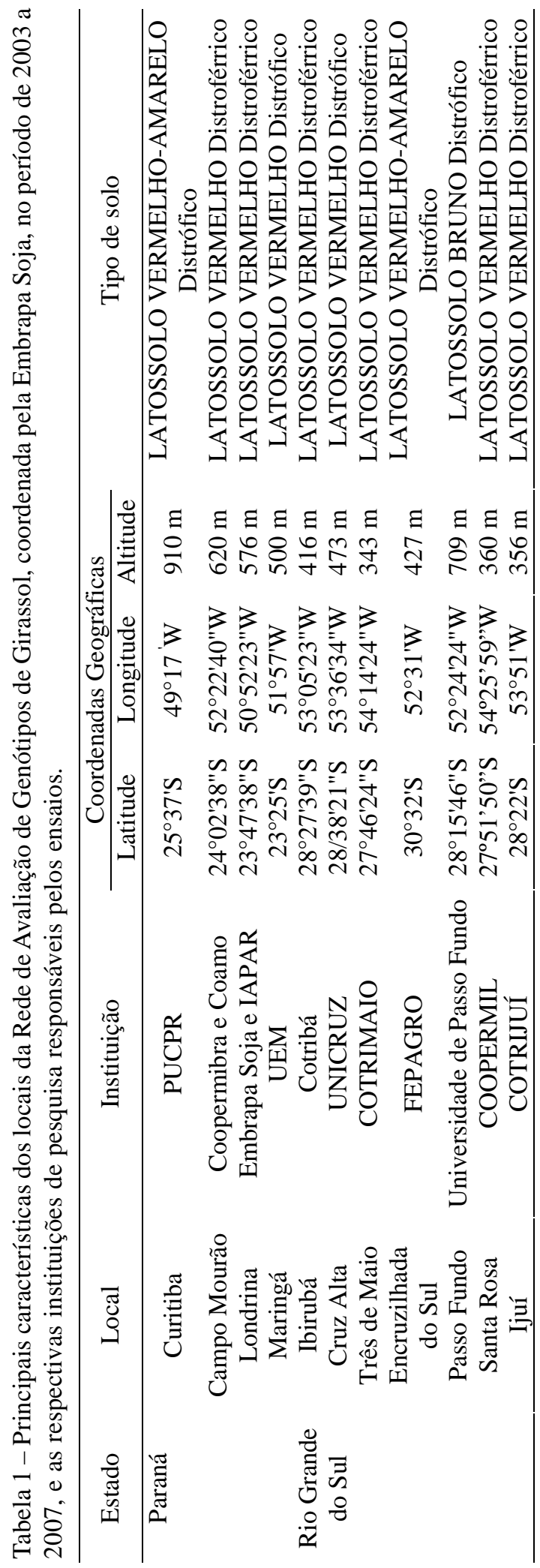


Genótipos de girassol híbridos (simples e duplos) e variedades (populações de polinização aberta) pertencentes às empresas Advanta, CATI, Dow AgroSciences, Embrapa Soja, La Tijereta e Helianthus do Brasil, foram testados. Como testemunha de híbridos, foram utilizados M 734 e Agrobel 960 e, como testemunha de variedade, o cultivar Embrapa 122. O número total de experimentos, genótipos e as safras avaliadas foram, respectivamente, oito e dez em 2004/2005, quatro e doze em 2005/2006 e cinco e quinze em 2006/2007. Na colheita, a população de plantas foi superior ao mínimo de quatro de plantas por $\mathrm{m}^{2}$ em todos os ensaios estudados. Cada grupo de genótipo foi avaliado durante dois anos, nos Ensaios Finais de Primeiro e de Segundo Ano.

As análises de variância foram realizadas para os componentes de rendimento $\left(\mathrm{kg} \mathrm{ha}^{-1}\right)$, aferidos em cada local e ano. Como nem sempre os locais de testes dos ensaios finais de primeiro ano foram os mesmos dos de segundo ano, foi realizada uma análise conjunta de ambientes (local e ano específicos) para cada grupo de genótipos. Para isso, verificou-se a existência de homogeneidade, das variâncias residuais obtidas nas análises de ambientes, sempre que a razão, entre o maior e o menor quadrado médio residual, foi inferior a sete. Os ensaios que apresentaram coeficientes de variação (C.V.) superiores a $20 \%$ não foram considerados na análise conjunta (Pimentel Gomes, 1985).

Foi feito estudo de adaptabilidade e estabilidade dos genótipos, quanto ao rendimento de grãos e de óleo, utilizando-se os métodos de Eberhart \& Russell (1966), Lin \& Binns (1988) e Annicchiarico (1992). No método proposto por Eberhart \& Russel (1966), as análises são baseadas em análises de regressão linear simples, cujo modelo é dado por: $Y_{i j}=m+\beta I_{j}+\delta_{i j}+\bar{\varepsilon}_{i j}$, em que: $\mathrm{Y}_{\mathrm{ij}}=$ observação do cultivar i no ambiente $\mathrm{j} ; \mathrm{m}=$ média geral; $\beta=$ coeficiente de regressão; $I_{j}=$ índice ambiental obtido pela diferença entre a média de cada ambiente e a média geral. Dessa forma, $\quad \sum_{i=1}^{n} I_{j}=0 \quad ; \delta_{i j}=$ desvio da regressão do cultivar $\mathrm{i}$ no ambiente $\mathrm{j} ; \bar{\varepsilon}_{i j}=$ efeito do erro experimental médio. Nesse método, o genótipo ideal é aquele que apresenta alto rendimento, adaptabilidade geral $\left(\beta_{1 \mathrm{i}}=1\right)$ e alta previsibilidade ( $\sigma_{d i}^{2}=0$ ). A superioridade dos genótipos em rendimento foi verificada por meio do teste de ScottKnott, a 5\% de probabilidade, e por comparação da média geral de cada genótipo com a média das médias gerais das testemunhas. No método de Lin \& Binns (1988), a superioridade do desempenho de um genótipo nos vários locais de avaliação, indicada pelo valor de $\mathrm{P}_{\mathrm{i}}$, foi medida pelo quadrado médio das distâncias entre o desempenho desse genótipo e o desempenho do melhor genótipo em cada local. $\mathrm{O}$ parâmetro de estabilidade $P_{i}$ é dado pela expressão: $P_{i}=\sum_{j=1}^{n}\left(X_{i j}-M_{j}\right)^{2} / 2 n$, onde: $P_{i}=$ índice de superioridaqe ao 1-esımo cuıtıvar; $X_{i j}=$ produtividade do iésimo cultivar no j-ésimo ambiente; $M_{j}=$ resposta máxima obtida entre todos os cultivares no j-ésimo ambiente; $\mathrm{n}=$ número de ambientes. Essa expressão pode ser desdobrada em:

$$
P_{i}=\left[n\left(\bar{X}_{i}-\bar{M}\right)^{2}+\sum_{j=1}^{n}\left(\bar{X}_{i j}-\bar{X}_{i}-M_{j}+\bar{M}\right)^{2}\right] / 2 \mathrm{n}
$$

onde: $\overline{\mathrm{X}}_{\mathrm{i} .}=\sum_{\mathrm{j}=1}^{\mathrm{n}} \mathrm{X}_{\mathrm{ij}} / \mathrm{il}$ e $\overline{\mathrm{M}}=\sum_{\dot{\mathrm{j}} 1}^{\mathrm{h}} \mathrm{ML}_{\mathrm{j}} / \mathrm{hl}$, em que: $\mathrm{X}_{\mathrm{i}}=\mathrm{a}$ média das produtividades dos cultivares obtidas nos $\mathrm{n}$ ambientes; $\overline{\mathrm{M}}=$ a média das respostas máximas de todos os cultivares em todos os ambientes. No método proposto por Annicchiarico (1992), a seleção dos genótipos foi realizada com base no índice de recomendação $\left(I_{i}\right)$, considerando um coeficiente de confiança de $75 \%$. Este índice é obtido pela seguinte expressão:

$I_{i}=\hat{\mu}_{i}-Z_{(1-\alpha)} \hat{\sigma}_{z i}$, em que: $\mathrm{I}_{\mathrm{i}}=$ índice de recomendação do desempenho de um determinado cultivar com relação à média do ambiente; $\hat{\mu}_{\mathrm{i}}=$ média geral do cultivar i em percentagem; $Z_{(1-\alpha)}$ : percentual $(1-\alpha)$ da função de distribuição normal acumulada; $\hat{\sigma}_{z i}$ : desvio-padrão dos valores percentuais; e $\alpha$ : nível de significância pré-fixado $(0,25)$. Os genótipos selecionados por este método foram aqueles que apresentaram índices de recomendação $(I)$ superiores (acima de 97) ou próximos de 100. Foi feita, também, a comparação dos índices desses genótipos com a média dos índices das testemunhas.

Todas as análises estatísticas foram realizadas por meio do programa computacional Genes (Cruz, 2001).

\section{RESULTADOS E DISCUSSÃO}

As médias gerais de rendimento de grãos obtidas nos ensaios variaram de $2.003 \mathrm{~kg} \mathrm{ha}^{-1}$ (safra 2006/2007) a $2.328 \mathrm{~kg} \mathrm{ha}^{-1}$ (safra 2005/2006) e para rendimento de óleo, a variação foi de $869 \mathrm{~kg} \mathrm{ha}^{-1}(2004 / 2005)$ a $1.040 \mathrm{~kg} \mathrm{ha}^{-1}$ (2005/ 2006) (Tabela 2). Essas médias foram superiores a média nacional (aproximadamente $1.500 \mathrm{~kg} \mathrm{ha}^{-1}$ ), para o período correspondente (CONAB, 2007). Os coeficientes de variação 
(C.V.), das análises de variância conjunta para os componentes de rendimento, foram classificados como médios (Tabela 2), de acordo com a classificação de Pimentel Gomes (1985), indicando boa precisão experimental. Nessas análises, diferenças significativas $(\mathrm{P}<0,01)$ entre os genótipos foram observadas, sendo necessária a aplicação de testes de média para a sua discriminação.

Apesar dos valores médios de C.V., o teste de ScottKnott a 5\% de probabilidade apontou, geralmente, diferenças significativas entre os genótipos somente quando houve grande distância entre suas médias (Tabelas 3 e 4), como observado por Porto et al. (2007, 2008). Nesse estudo, na safra 2005/2006, por exemplo, para o rendimento de grãos, esse teste de agrupamento $(\mathrm{P}<0,05)$ diferenciou apenas a única variedade testada (população de polinização aberta) dos demais genótipos (híbridos), sendo que os híbridos classificados no mesmo grupo tiveram uma diferença entre eles de $601 \mathrm{~kg} \mathrm{ha}^{-1}$ (Tabela 3). Contudo, quando verificado o ranqueamento dos genótipos em cada ambiente testado, foi possível observar razoáveis diferenças entre eles, como na safra 2004/2005, em que o híbrido M 734 ocupou os primeiros postos e a variedade Embrapa 122 os últimos postos na maioria dos locais (Tabela 5). Além disso, em todos os anos avaliados, nenhum híbrido superou as testemunhas com base no teste de média utilizado. Resultados similares foram obtidos, também, por Porto et al. (2007, 2008).
Em virtude do teste de Scott-Knott apontar diferenças significativas entre os genótipos, apenas quando houve grande distância entre suas médias, a seleção de genótipos de girassol foi feita por meio da comparação do desempenho de cada um com a média das testemunhas dos ensaios. Assim, os materiais selecionados foram aqueles que apresentaram média geral superior (em valor numérico) à média das testemunhas. A utilização desse critério reduziu o número de genótipos selecionados em relação ao teste de Scott-Knott (Tabelas 3 e 4).

Na safra 2004/2005 (dados obtidos do Ensaio Final de Primeiro Ano 2003/2004 e do Ensaio Final de Segundo Ano 2004/2005), nenhum genótipo superou a média das testemunhas de híbridos, para os componentes de rendimento avaliados (Tabelas 3 e 4). Nas demais safras, para o rendimento de grãos, essa superioridade foi mostrada pelos híbridos VDH 487 (2005/2006), Agrobel 959 (2005/2006), Helio 253 (2006/2007) e Helio 360 (2006/ 2007) (Tabela 3). Para rendimento de óleo, os híbridos que se destacaram foram VDH 487 (2005/2006), Agrobel 959 (2005/2006), V 03005 (2005/2006), MG 52 (2005/2006), V 20038 (2005/2006), EXP 1441 (2006/2007), Helio 360 (2006/2007) e Helio 253 (2006/2007) (Tabela 4). Assim, somente os híbridos VDH 487, Agrobel 959, Helio 253 e Helio 360 se destacaram para os dois componentes de rendimento avaliados. 
Tabela 2 - Análise conjunta para rendimento de grãos e de óleo de cultivares de girassol, testados na Rede de Ensaios de Avaliação de Genótipos de Girassol, coordenada pela Embrapa Soja, no período de 2003 a 2007.

\begin{tabular}{|c|c|c|c|}
\hline \multirow{2}{*}{ Fonte de Variação } & \multirow{2}{*}{ G.L. } & \multicolumn{2}{|c|}{ Quadrado Médio } \\
\hline & & Rendimento de grãos $\left(\mathrm{kg} \mathrm{ha}^{-1}\right)$ & Rendimento de óleo $\left(\mathrm{kg} \mathrm{ha}^{-1}\right)$ \\
\hline \multicolumn{4}{|l|}{ Safra $2004 / 2005^{1 /}$} \\
\hline Blocos/Ambientes & 24 & $240.928,12$ & $53.822,86$ \\
\hline Tratamentos $(\mathrm{T})$ & 9 & $2.160 .963,13 * *$ & $336.907,85 * *$ \\
\hline Ambientes (A) & 7 & $8.603 .551,22 * *$ & $2.115 .528,44 * *$ \\
\hline $\mathrm{T} \times \mathrm{A}$ & 63 & $206.986,78^{* *}$ & $48.094,78 * *$ \\
\hline Resíduo & 216 & $98.001,94$ & $20.768,65$ \\
\hline Média & & 2.048 & 869 \\
\hline $\mathrm{CV}(\%)$ & & 15,28 & 16,57 \\
\hline \multicolumn{4}{|l|}{ Safra $2005 / 2006$} \\
\hline Blocos/Ambientes & 12 & $314.040,33$ & $86.259,99$ \\
\hline Tratamentos $(\mathrm{T})$ & 11 & $1.382 .788,07 * *$ & $418.492,27 * *$ \\
\hline Ambientes (A) & 3 & $12.861 .865,68 * *$ & $4.073 .172,22 * *$ \\
\hline $\mathrm{T} \times \mathrm{A}$ & 33 & $281.663,48 * *$ & $90.933,65 * *$ \\
\hline Resíduo & 132 & $115.328,92$ & $25.934,81$ \\
\hline Média & & 2.328 & 1.040 \\
\hline CV $(\%)$ & & 14,58 & 15,47 \\
\hline \multicolumn{4}{|l|}{ Safra $2006 / 2007$} \\
\hline Blocos/Ambientes & 15 & $265.783,43$ & $47.543,98$ \\
\hline Tratamentos $(\mathrm{T})$ & 14 & $2.855 .708,33 * *$ & $554.971,66 * *$ \\
\hline Ambientes (A) & 4 & $5.869 .487,70 * *$ & $1.482 .272,42 * *$ \\
\hline $\mathrm{T} \times \mathrm{A}$ & 56 & $262.336,33 * *$ & $60.302,97 * *$ \\
\hline Resíduo & 210 & $109.833,65$ & $24.107,8616$ \\
\hline Média & & 2.003 & 912 \\
\hline $\mathrm{CV}(\%)$ & & 16,54 & 17,02 \\
\hline
\end{tabular}

** significativo a $1 \%$ de probabilidade, pelo teste $\mathrm{F}$.

${ }^{1 /}$ Avaliações realizadas na safra 2004/2005 incluíram os dados experimentais obtidos no Ensaio Final de Primeiro Ano 2003/2004

e Ensaio Final de Segundo Ano 2004/2005, com procedimento similar para os demais anos de avaliação. 
Tabela 3 - Parâmetros de estabilidade e adaptabilidade de híbridos $(\mathrm{H})$ e variedades (V) de girassol, obtidos por meio dos métodos de Eberhart \& Russel (1966), Lin \& Binns (1988) e Annicchiarico (1992), para o rendimento de grãos (kg ha' ${ }^{-1}$ ), avaliado entre os anos de 2004 e 2007.

\begin{tabular}{|c|c|c|c|c|c|}
\hline \multicolumn{6}{|c|}{ Rendimento de grãos $\left(\mathrm{kg} \mathrm{ha}^{-1}\right)$} \\
\hline \multirow[b]{2}{*}{ Genótipo } & \multicolumn{3}{|c|}{ Eberhart e Russel (1966) } & \multirow[b]{2}{*}{$\mathbf{P}_{\mathrm{i}}$} & \multirow[b]{2}{*}{$\mathrm{I}_{i}^{9 /}$} \\
\hline & Média & $\beta_{1 \mathrm{i}}{ }^{7 /}$ & $\sigma_{\mathrm{di}}^{27 /}$ & & \\
\hline \multicolumn{6}{|l|}{ Safra $2004 / 2005^{1 /}$} \\
\hline M $734(\mathrm{H})^{2 /}$ & $2.542 \mathrm{a}^{5 /}$ & $1,12^{\mathrm{ns} 6 \mathrm{l}}$ & $39417,59 * *$ & 772,85 & 120,66 \\
\hline Agrobel $960(\mathrm{H})^{2 /}$ & $2.239 \mathrm{a}$ & $1,25 * *$ & $15717,66^{\mathrm{ns}}$ & $100.350,12$ & 104,59 \\
\hline BRHS $04(\mathrm{H})$ & $2.165 \mathrm{a}$ & $1,11^{\mathrm{ns}}$ & $27919,22 * *$ & $105.725,49$ & 102,04 \\
\hline Helio $355(\mathrm{H})$ & $2.093 \mathrm{a}$ & $1,06 *$ & $-12426,56^{\mathrm{ns}}$ & 133.03069 & 101,49 \\
\hline BRHS $01(\mathrm{H})$ & $2.066 \mathrm{a}$ & $0,67 *$ & $18798,49^{\text {ns }}$ & $188.526,75$ & 98,15 \\
\hline BRHS $03(\mathrm{H})$ & $2.030 \mathrm{a}$ & $1,02^{\mathrm{ns}}$ & $61880,77 * *$ & $205.545,93$ & 95,28 \\
\hline BRHS $02(\mathrm{H})$ & $2.023 \mathrm{a}$ & $0,84^{\mathrm{ns}}$ & $39550,22 * *$ & $183.322,83$ & 96,4 \\
\hline BRHS $05(\mathrm{H})$ & $2.004 \mathrm{a}$ & $1,18^{\mathrm{ns}}$ & $9795,07^{11 s}$ & 181.509 .63 & 95,49 \\
\hline BRIIS 06 (II) & $1.693 \mathrm{a}$ & $0,88^{\text {ns }}$ & $-6083,67^{\text {ns }}$ & $379.007,47$ & 81.27 \\
\hline Embrapa $122(\mathrm{~V})^{3 /}$ & $1.621 \mathrm{a}$ & $0,83^{\text {ns }}$ & $22325,09^{\text {пs }}$ & $476.026,99$ & 75,93 \\
\hline $\mathrm{MG}^{4 /}$ & 2.048 & - & - & $195.381,9$ & - \\
\hline MTH & 2.390 & - & - & $50.561,48$ & 112,62 \\
\hline \multicolumn{6}{|l|}{ Safra $2005 / 2006$} \\
\hline VDH $487(\mathrm{H})$ & $2.669 \mathrm{a}^{5 /}$ & $1,23^{\mathrm{n} s 6 /}$ & $8038899 *$ & $44.466,13$ & 110,82 \\
\hline $\mathrm{M} 734(\mathrm{H})^{2}$ & $2.647 \mathrm{a}$ & $0,77^{\mathrm{ns}}$ & $24231,14^{\mathrm{nIS}}$ & 53.768 .42 & 111,9 \\
\hline Agrobel $959(\mathrm{H})$ & $2.593 \mathrm{a}$ & $1,01^{\mathrm{ns}}$ & $23200,37^{\mathrm{ns}}$ & $57.289,80$ & 109,44 \\
\hline BRHS $08(\mathrm{H})$ & $2.416 \mathrm{a}$ & $0,57 * *$ & $2856,73^{\mathrm{ns}}$ & $139.487,34$ & 102,35 \\
\hline $\mathrm{V} 03005(\mathrm{H})$ & $2.416 \mathrm{a}$ & $1,49 *$ & $12626,87^{\mathrm{ns}}$ & $148.707,88$ & 99,36 \\
\hline $\mathrm{V} 20038(\mathrm{H})$ & $2.393 \mathrm{a}$ & $0,77^{\mathrm{ns}}$ & $106734,83 * *$ & $152.681,92$ & 99,74 \\
\hline $\mathrm{MG} 52(\mathrm{H})$ & $2.340 \mathrm{a}$ & $0,90^{\mathrm{ns}}$ & $9742223 * *$ & 173.987 .87 & 97,17 \\
\hline MG $50(\mathrm{H})$ & $2.326 \mathrm{a}$ & $0,96^{\mathrm{ns}}$ & $98717,78 * *$ & $188.215,16$ & 96,43 \\
\hline $\mathrm{V} 20044$ (II) & $2.249 \mathrm{a}$ & $1,40 * *$ & $10646,02^{\mathrm{ns}}$ & $226.153,75$ & 92,41 \\
\hline Agrobel $960(\mathrm{H})^{2 /}$ & $2.243 \mathrm{a}$ & $1.26^{\mathrm{ns}}$ & $7390,99^{\text {пs }}$ & 218.369 .90 & 93,11 \\
\hline BRHS $09(\mathrm{H})$ & $2.068 \mathrm{a}$ & $0,80^{\mathrm{ns}}$ & $4597,62^{\text {ns }}$ & $346.858,31$ & 87,26 \\
\hline Embrapa $122(\mathrm{~V})^{3 /}$ & $1.578 \mathrm{~b}$ & $0,77^{\mathrm{ns}}$ & $-22465,03^{\mathrm{ns}}$ & $858.035,12$ & 66,63 \\
\hline $\mathrm{MG}^{4 /}$ & 2.328 & - & - & $217.335,13$ & - \\
\hline MTH & 2.445 & - & - & $136.069,16$ & 102,5 \\
\hline \multicolumn{6}{|l|}{ Safra $2006 / 2007$} \\
\hline M $734(\mathrm{H})^{2 /}$ & $2.553 \mathrm{a}^{5 /}$ & $0,77^{\mathrm{n} n \mathrm{~s} /}$ & $35037,63^{\mathrm{ns}}$ & 35.63295 & 124,6 \\
\hline Helio $253(\mathrm{H})$ & $2.498 \mathrm{a}$ & $1,73 *$ & $56315,05 * *$ & 69.484 .87 & 119,19 \\
\hline Helio $360(\mathrm{H})$ & $2.427 \mathrm{a}$ & $0,95^{\mathrm{ns}}$ & $44361,22^{\mathrm{ns}}$ & $73.100,34$ & 118,13 \\
\hline EXP $1441(\mathrm{H})$ & $2.349 \mathrm{a}$ & $0,62^{\text {ns }}$ & $-8193,4072^{\mathrm{ns}}$ & 91.399 .26 & 115,45 \\
\hline BRSGira $06(\mathrm{H})$ & $2.323 \mathrm{a}$ & $1,26^{\mathrm{ns}}$ & $29211,92^{\mathrm{ns}}$ & $125.333,53$ & 112,98 \\
\hline Agrobel $960(\mathrm{H})^{2 /}$ & $2.183 \mathrm{a}$ & $1,10^{\mathrm{ns}}$ & $33413,40^{\mathrm{ns}}$ & $177.668,02$ & 105,94 \\
\hline Helio $362(\mathrm{H})$ & $2.183 \mathrm{a}$ & $1,66 * *$ & $1705,95^{\mathrm{ns}}$ & $192.456,05$ & 104,41 \\
\hline BRSGira $05(\mathrm{H})$ & $1.918 \mathrm{~b}$ & $0,16^{* * *}$ & $-17593,45^{\mathrm{ns}}$ & $371.018,88$ & 93,41 \\
\hline BRSGira $07(\mathrm{H})$ & $1.886 \mathrm{~b}$ & $0,34 * *$ & $889,37^{\text {ns }}$ & $390.098,97$ & 91,77 \\
\hline Catissol (V) & $1.775 \mathrm{~b}$ & $0,48 * *$ & $-2010,73^{\mathrm{ns}}$ & $498.096,65$ & 86,77 \\
\hline BRSGira $04(\mathrm{H})$ & $1.747 \mathrm{~b}$ & $0,51^{\mathrm{ns}}$ & $33705,63^{\mathrm{ns}}$ & $543.425,94$ & 84,69 \\
\hline BRSGira $02(\mathrm{~V})$ & $1.687 \mathrm{~b}$ & $1,36^{\mathrm{ns}}$ & $34719,32^{\text {ns }}$ & $602.055,33$ & 79,03 \\
\hline BRSGira 01 (V) & $1.531 \mathrm{~b}$ & $1,55 *$ & $-2481,61 \mathrm{~ns}$ & $757.457,71$ & 70,98 \\
\hline Embrapa $122(\mathrm{~V})^{3 /}$ & $1.510 \mathrm{~b}$ & $0,91^{\mathrm{ns}}$ & $116165,02 * *$ & $830.519,34$ & 71,17 \\
\hline BRSGira 03 (V) & $1.473 \mathrm{~b}$ & $1,51^{\mathrm{ns}}$ & $-11395,02^{\mathrm{ns}}$ & $826.414,96$ & 68,33 \\
\hline $\mathrm{MG}^{4 /}$ & 2.003 & - & - & $372.277,52$ & - \\
\hline MTH & 2.368 & - & - & $106.650,48$ & 115,27 \\
\hline MTV & 1.510 & - & - & $830.519,34$ & 71,17 \\
\hline
\end{tabular}

${ }^{1 / A v a l i a c ̧ o ̃ e s ~ r e a l i z a d a s ~ n a ~ s a f r a ~ 2004 / 2005 ~ i n c l u i ́ r a m ~ o s ~ d a d o s ~ e x p e r i m e n t a i s ~ o b t i d o s ~ n o ~ E n s a i o ~ F i n a l ~ d e ~ P r i m e i r o ~ A n o ~ 2003 / 2004 ~ e ~}$ Ensaio Final de Segundo Ano 2004/2005, com procedimento similar para os demais anos de avaliação.

${ }^{2 / G e n o ́ t i p o ~ t e s t e m u n h a ~ d o ~ e n s a i o ~ p a r a ~ c o m p a r a c ̧ a ̃ o ~ d e ~ h i ́ b r i d o s . ~}$

${ }^{3 /}$ Genótipo testemunha do ensaio para comparação de variedades

${ }^{4 /} \mathrm{MG}=$ Média geral; MTH = Média das testemunhas de híbridos; MTV = Média da testemunha de variedades

${ }^{5 / M e ́ d i a s ~ s e g u i d a s ~ d a ~ m e s m a ~ l e t r a, ~ n a ~ c o l u n a, ~ n a ̃ o ~ d i f e r e m ~ s i g n i f i c a t i v a m e n t e ~ p e l o ~ t e s t e ~ d e ~ S c o t t-K n o t t ~ a ~ 5 \% ~ d e ~ p r o b a b i l i d a d e . ~}$

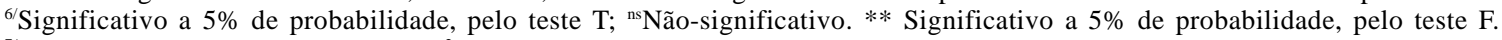

${ }^{7 /}$ Adaptabilidade $\left(ß_{1 \mathrm{j}}\right)$, estabilidade $\left(\mathrm{s}^{2}\right)$.

${ }^{8 /} \mathrm{Pi}=$ Parâmetro de adaptabilidade de Lin \& Binns (1988).

${ }^{9} \mathrm{I}_{\mathrm{i}}=$ índice de recomendação do método do Annicchiarico (1992).

Ciênc. agrotec., Lavras, v. 33, n. 5, p. 1195-1204, set./out., 2009 
Tabela 4 - Parâmetros de estabilidade e adaptabilidade de híbridos (H) e variedades (V) de girassol, obtidos por meio dos métodos de Eberhart \& Russel (1966), Lin \& Binns (1988) e Annicchiarico (1992), para o rendimento de óleo (kg ha $\left.{ }^{-1}\right)$, avaliado entre os anos de 2004 e 2007.

\begin{tabular}{|c|c|c|c|c|c|}
\hline \multirow[b]{2}{*}{ Genótipo } & \multicolumn{3}{|c|}{$\begin{array}{l}\text { Rendimento de óleo }\left(\mathrm{kg} \mathrm{ha}^{-1}\right) \\
\text { Eberhart e Russel (1960) }\end{array}$} & \multirow[b]{2}{*}{$\mathbf{P}_{\mathbf{i}}$} & \multirow[b]{2}{*}{$\mathbf{I}_{\mathbf{i}}{ }^{9 /}$} \\
\hline & Mćdia & $\beta_{1 i}{ }^{7 /}$ & $\sigma_{\mathrm{di}}^{27 /}$ & & \\
\hline \multicolumn{6}{|l|}{ Safra $2004 / 2005^{1 /}$} \\
\hline Agrobel $960(\mathrm{H})^{2 /}$ & $994 a^{5 /}$ & $1,38 * * 6 /$ & $4096,26^{\mathrm{ns}}$ & $10.760,11$ & 107,6 \\
\hline M 734 $(\mathrm{H})^{2 !}$ & $976 \mathrm{a}$ & $0,89^{\text {ns }}$ & $6913,51 * *$ & $7.698,39$ & 110,27 \\
\hline BRHS $04(\mathrm{H})$ & $943 \mathrm{a}$ & $1,08^{\mathrm{ns}}$ & $5917,89 * *$ & $12.610,13$ & 104,67 \\
\hline Helio $355(\mathrm{H})$ & $924 \mathrm{a}$ & $1,21 \%$ & $-2606,84^{\mathrm{ns}}$ & $16.382,57$ & 104,44 \\
\hline BRHS $05(\mathrm{H})$ & $888 \mathrm{a}$ & $1,21 *$ & $1330,31^{\mathrm{ns}}$ & 22.467 .28 & 98,14 \\
\hline BRHS $01(\mathrm{H})$ & $858 \mathrm{a}$ & $0,64 * *$ & $4055,55^{\mathrm{ns}}$ & $32.334,33$ & 99,36 \\
\hline BRHS $03(\mathrm{H})$ & $849 a$ & $1,02^{\mathrm{ns}}$ & $8683,02 * *$ & $37.220,42$ & 93,82 \\
\hline BRHS $02(\mathrm{H})$ & $844 a$ & $0,81^{\mathrm{ns}}$ & $8875,10^{* *}$ & $41.907,99$ & 92,19 \\
\hline BRHS $06(\mathrm{H})$ & $771 \mathrm{a}$ & $0,95^{\mathrm{ns}}$ & $-947,91^{\mathrm{ns}}$ & $49.409,02$ & 86,41 \\
\hline Embrapa $122(\mathrm{~V})^{3 /}$ & $650 a$ & $0,78^{* *}$ & $4091,93^{\mathrm{ns}}$ & $101.252,45$ & 70,71 \\
\hline $\mathrm{MG}^{4 /}$ & 869 & - & - & 33.204 .27 & - \\
\hline MTH & 985 & - & - & $9.229,25$ & 108,93 \\
\hline \multicolumn{6}{|l|}{ Safra 2005/2006 } \\
\hline VDH $487(\mathrm{H})$ & $1.303 \mathrm{a}^{5 /}$ & $1,36 * * 6$ & $24438,14 * *$ & 3. 163,50 & 120,7 \\
\hline Agrobel $959(\mathrm{H})$ & $1.177 \mathrm{a}$ & $0,97^{\mathrm{ns}}$ & $1269,42^{\mathrm{ns}}$ & $25.881,66$ & 111,73 \\
\hline $\mathrm{V} 03005(\mathrm{H})$ & $1.130 \mathrm{a}$ & $1,60 \%$ & $1737,78^{\mathrm{ns}}$ & $32.677,32$ & 102,17 \\
\hline MG 52 (II) & $1.093 \mathrm{a}$ & $0,96^{\mathrm{ns}}$ & $33109,62 * *$ & $46.611,63$ & 100,56 \\
\hline $\mathrm{M} 734(\mathrm{H})^{2 /}$ & $1.089 \mathrm{a}$ & $0,64 *$ & $22861,83^{* * *}$ & 66.405 .81 & 102.25 \\
\hline $\mathrm{V} 20038(\mathrm{H})$ & $1.070 \mathrm{a}$ & $0,82^{\mathrm{ns}}$ & $23930,50 * *$ & $52.254,36$ & 99,85 \\
\hline $\mathrm{V} 20044(\mathrm{H})$ & $1.059 \mathrm{a}$ & $1,41^{\text {** }}$ & $-299,60^{\mathrm{ns}}$ & 43.178 .25 & 97,08 \\
\hline $\mathrm{MG} 50(\mathrm{H})$ & $1.039 \mathrm{a}$ & $0,88^{\mathrm{ns}}$ & $20740,50 * *$ & $67.939,05$ & 96,57 \\
\hline Agrobel $960(\mathrm{H})^{2 /}$ & $1.033 \mathrm{a}$ & $1,33 *$ & $-153,87^{\mathrm{ns}}$ & $52.236,73$ & 95,08 \\
\hline BRHS $08(\mathrm{H})$ & $979 a$ & $0,51 \%$ & $-3216,62^{\mathrm{ns}}$ & $96.067,43$ & 93,26 \\
\hline BRHS $09(\mathrm{H})$ & $856 \mathrm{~b}$ & $0,82^{\mathrm{ns}}$ & $6570,50^{\mathrm{ns}}$ & $136.932,88$ & 79,79 \\
\hline Embrapa $122(\mathrm{~V})^{3 /}$ & $656 \mathrm{~b}$ & $0,64 \%$ & $-5868,33^{\text {IIS }}$ & $256.981,68$ & 62,41 \\
\hline $\mathrm{MG}^{4 / 2}$ & 1.041 & - & - & $73.360,86$ & - \\
\hline MTH & 1.061 & - & - & 59.32127 & 98,66 \\
\hline \multicolumn{6}{|l|}{ Safra $2006 / 2007$} \\
\hline $\operatorname{EXP} 1441(\mathrm{H})$ & $1.136 \mathrm{a}^{5 /}$ & $0,69^{\mathrm{ns6} /}$ & $-1885,81^{\mathrm{ns}}$ & $6.431,40$ & 122,89 \\
\hline Helio $360(\mathrm{H})$ & $1.129 \mathrm{a}$ & $1,17^{\mathrm{ns}}$ & $16194,37 * *$ & $6.317,52$ & 119,99 \\
\hline Helio $253(\mathrm{H})$ & $1.127 \mathrm{a}$ & $1,64 \%$ & $12047,08^{* * *}$ & 9.650 .79 & 11799 \\
\hline Agrobel $960(\mathrm{H})^{2 /}$ & $1.035 \mathrm{a}$ & $1,15^{\mathrm{ns}}$ & $5112,68^{\mathrm{ns}}$ & $18.675,10$ & 110,49 \\
\hline BRSGira $06(\mathrm{H})$ & $1.027 \mathrm{a}$ & $1,24^{\mathrm{ns}}$ & $7869,69^{\mathrm{ns}}$ & $27.471,24$ & 109,21 \\
\hline M734 $(\mathrm{H})^{2 !}$ & $1.019 \mathrm{a}$ & $0,46 * *$ & $7286,91^{\mathrm{ns}}$ & $27.434,22$ & 108,89 \\
\hline Helio $362(\mathrm{H})$ & $977 \mathrm{a}$ & $1,62 * *$ & $-2259,47^{\mathrm{ns}}$ & $34.922,30$ & 102,5 \\
\hline BRSGira $05(\mathrm{H})$ & $893 b$ & $0,29 * *$ & $-3914,05^{\mathrm{ns}}$ & $57.555,67$ & 95,92 \\
\hline BRSGira $04(\mathrm{H})$ & $864 \mathrm{~b}$ & $0,78^{\mathrm{ns}}$ & $13388,85 * *$ & $71.635,38$ & 91,58 \\
\hline BRSGira $07(\mathrm{H})$ & $855 b$ & $0,44 \%$ & $-3548,60^{\mathrm{ns}}$ & $68.616,69$ & 92,11 \\
\hline Catissol (V) & $780 \mathrm{~b}$ & $0,48 \%$ & $-801,8^{n s}$ & $102.356,77$ & 83,81 \\
\hline BRSGira 01 (V) & $771 \mathrm{~b}$ & $1,46^{\mathrm{ns}}$ & $8679,64^{\mathrm{ns}}$ & $108.092,16$ & 78,84 \\
\hline BRSGira 02 (V) & $751 \mathrm{~b}$ & $1,36^{\mathrm{ns}}$ & $4624,53^{\mathrm{ns}}$ & $113.075,58$ & 76,65 \\
\hline BRSGira 03 (V) & $665 \mathrm{~b}$ & $1,32^{\mathrm{ns}}$ & $4644,28^{\mathrm{ns}}$ & $157.578,12$ & 67,44 \\
\hline Embrapa $122(\mathrm{~V})^{3 /}$ & $646 b$ & $0,82^{\text {ns }}$ & $27898,72 * *$ & $180.345,33$ & 66,49 \\
\hline $\mathrm{MG}^{4 /}$ & 912 & - & - & 66.010 .55 & - \\
\hline MTH & 1.027 & - & - & $23.054,66$ & 109,69 \\
\hline MTV & 646 & - & - & $180.345,33$ & 66,49 \\
\hline
\end{tabular}

${ }^{1 / A v a l i a c ̧ o ̃ e s ~ r e a l i z a d a s ~ n a ~ s a f r a ~ 2004 / 2005 ~ i n c l u i ́ r a m ~ o s ~ d a d o s ~ e x p e r i m e n t a i s ~ o b t i d o s ~ n o ~ E n s a i o ~ F i n a l ~ d e ~ P r i m e i r o ~ A n o ~} 2003 / 2004$ e Ensaio Final de Segundo Ano 2004/2005, com procedimento similar para os demais anos de avaliação.

${ }^{2 /}$ Genótipo testemunha do ensaio para comparação de híbridos.

${ }^{3 /}$ Genótipo testemunha do ensaio para comparação de variedades.

${ }^{4} \mathrm{MG}=$ Média geral; $\mathrm{MTH}=$ Média das testemunhas de híbridos; MTV = Média da testemunha de variedades.

${ }^{5 /}$ Médias seguidas da mesma letra, na coluna, não diferem significativamente pelo teste de Scott-Knott a 5\% de probabilidade.

${ }^{6}$ Significativo a $5 \%$ de probabilidade, pelo teste $\mathrm{T}$; ${ }^{n} \mathrm{Não}-$ significativo. ** Significativo a $5 \%$, pelo teste $\mathrm{F}$.

${ }^{7}$ Adaptabilidade $\left(\beta_{1}\right)$, estabilidade $\left(\mathrm{s}^{2}\right)$.

${ }^{8 /} \mathrm{Pi}=$ Parâmetro de adaptabilidade de Lin \& Binns (1988).

${ }^{9} \mathrm{I}_{\mathrm{i}}=$ índice de recomendação do método do Annicchiarico (1992). 


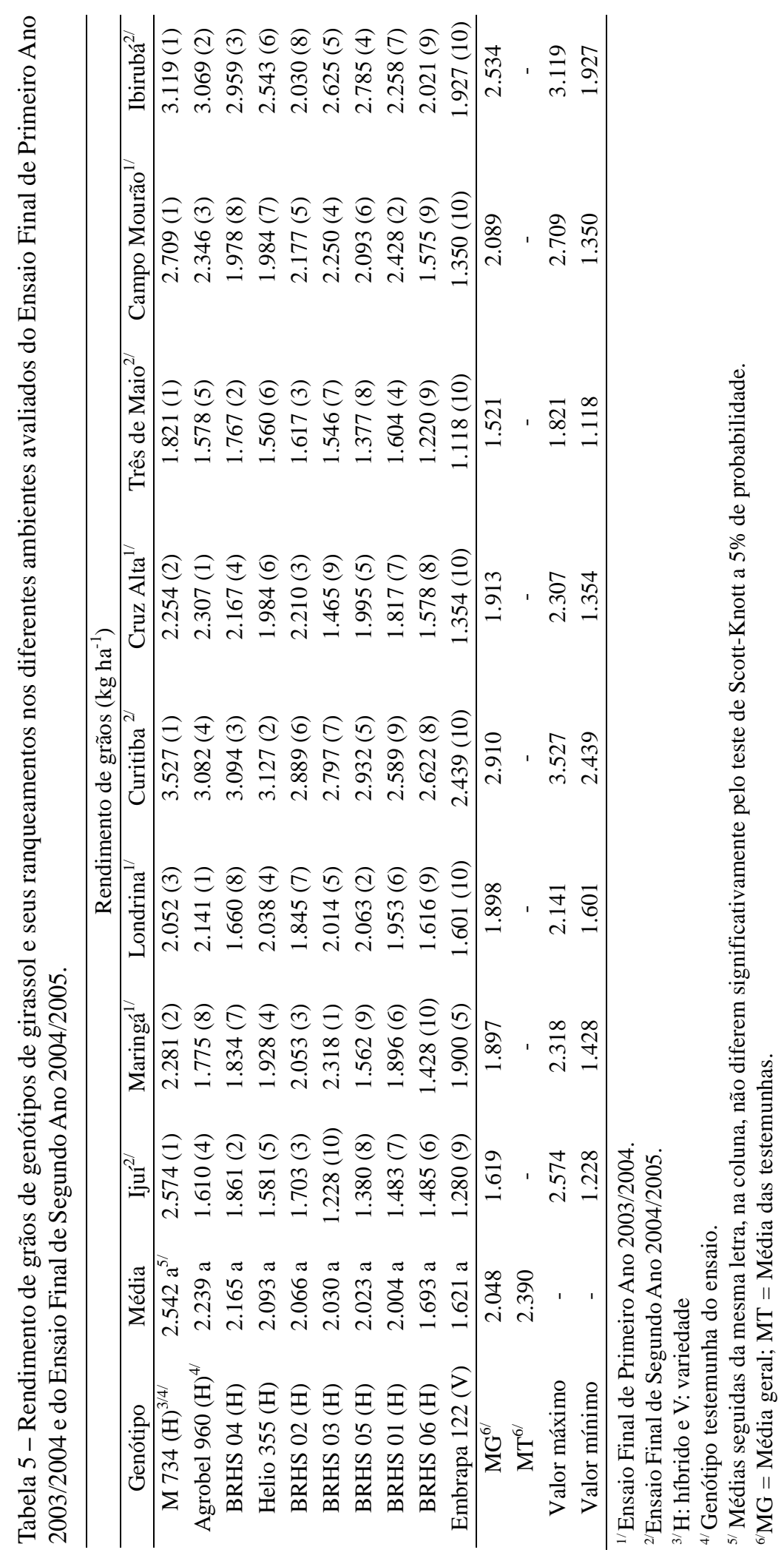

Ciênc. agrotec., Lavras, v. 33, n. 5, p. 1195-1204, set./out., 2009 
Nas safras 2004/2005 e 2005/2006, a única variedade testada (Embrapa 122) teve média inferior à média dos híbridos M 734 e Agrobel 960 de 34,01\% e 38,17\%, respectivamente, para rendimento de grãos (Tabela 3 ). Nessas safras, a variedade Embrapa 122 foi comparada com os demais híbridos, pois nesses anos não se tinha testemunha para variedades nos ensaios. Apesar de ter sido menos produtiva que os híbridos comerciais, o uso desta ou de outras variedades pode ser interessante para pequenos produtores menos tecnificados, uma vez que o custo da semente híbrida é maior. Na safra 2006/2007 (Ensaio Final de Primeiro Ano 2005/2006 e do Ensaio Final de Segundo Ano 2006/2007), as variedades Catissol, BRSGira 01 e BRSGira 02 tiveram médias superiores a Embrapa 122 para rendimento de grãos e de óleo, enquanto que BRSGira 03 se destacou apenas para rendimento de óleo (Tabelas 3 e 4).

Nas análises de variância conjuntas para rendimentos de grãos e de óleo, diferenças significativas $(\mathrm{P}<0,01)$ na interação genótipo $\mathrm{x}$ ambiente foram observadas pelo teste $\mathrm{F}$ (Tabela 2), indicando que a diferença no comportamento entre genótipos variou em função do ambiente avaliado e, por consequência, revelando a importância de estudos de adaptabilidade e estabilidade dos genótipos.

Dentre os genótipos selecionados por meio da comparação do desempenho de cada genótipo com a média das testemunhas, entre 2003 e 2007, para rendimento de grãos, somente os híbridos Agrobel 959 (2005/2006) e Helio $360(2006 / 2007)$ e a variedade BRSGira 02 (2006/2007) foram considerados ideais pelo método de Eberhart \& Russel (1966), por apresentarem adaptabilidade geral $\left(\beta_{1 \mathrm{i}}=1\right) \mathrm{e}$ boa previsibilidade ( $\sigma_{d i}^{2}$ nulo). Para rendimento de óleo, os genótipos ideais foram os híbridos Agrobel 959 (2005/ 2006), EXP 1441 (2006/2007) e BRSGira 06 (2006/2007) e as variedades BRSGira 01, BRSGira 02 e BRSGira 03 (2006/ 2007). Por meio do estudo de adaptabilidade, verificou-se que alguns genótipos que tiveram bom desempenho apresentaram adaptabilidade a um ambiente específico. Para rendimento de grãos e de óleo, na safra 2006/2007 o híbrido Helio 253 mostrou adaptabilidade a ambientes favoráveis e a variedade Catissol, a ambientes desfavoráveis. A variedade BRSGira 01 (2006/2007) em rendimento de grãos e os híbridos VDH 487 (2005/2006) e V 03005 (2005/2006) em rendimento de óleo tiveram, também, adaptabilidade a ambientes favoráveis.

Ao comparar a média geral dos componentes de rendimento dos genótipos com os respectivos valores de $\mathrm{P}_{\mathrm{i}}$, estimados pelo método de Lin \& Binns (1988), verificou-se que as correlações foram negativas, variando de $-0,92$ a -0,99. Porto et al. (2007) ao avaliar genótipos de girassol e Carvalho et al. (2002) ao analisar linhagens de soja obtiveram, também, correlação negativa próxima à unidade entre estes parâmetros. Assim, a seleção dos genótipos com base na superioridade em relação à média dos $\mathrm{P}_{\text {is }}$ das testemunhas teve grande similaridade com a seleção com base na média geral das testemunhas. $\mathrm{O}$ híbrido EXP 1441 em rendimento de grãos (safra 2006/2007) e o híbrido V 20044 em rendimento de óleo (safra 2005/ 2006) não foram selecionados com base na média das testemunhas, porém foram indicados com base na média $\operatorname{dos} \mathrm{P}_{\text {is }}$.

Assim como no método de Lin \& Binns (1988), o parâmetro de adaptabilidade $\left(\mathrm{I}_{\mathrm{i}}\right)$ do método de Annicchiarico (1992) apresentou, também, uma alta correlação (acima 0,99 ) com a média geral, para os dois componentes de rendimento avaliados. Os genótipos que apresentaram média superior à média geral tiveram índice de recomendação $I_{i}$ superior (acima de 97) ou próximo de 100 e, consequentemente, foram selecionados (Tabelas 3 e 4). Além disso, como a maioria dos genótipos avaliados foi híbrido, a média geral tendeu a superar as médias das variedades (população de polinização aberta), sendo que nenhuma delas se destacou em nenhum componente de rendimento. Em virtude desses resultados, a seleção dos genótipos (híbrido ou variedade) foi feita, também, comparando o índice de cada genótipo com a média dos índices de recomendação das testemunhas (híbrido ou variedade). Nesse caso, a seleção foi mais rigorosa por selecionar um número menor de genótipos, mas possibilitou detectar variedades promissoras. Refletindo as correlações obtidas entre a média geral de cada genótipo e o respectivo $I_{i}$, a seleção dos genótipos, com base na superioridade em relação à média dos $I_{i}$ das testemunhas, teve grande similaridade com a seleção com base na média geral das testemunhas, exceto para o híbrido EXP 1441 e a variedade BRSGira 01 na safra 2006/ 2007, que foram selecionados para rendimento de grãos somente pelo primeiro e segundo método, respectivamente. Nesse estudo, a pouca discordância encontrada entre a análise da média geral e os parâmetros de Lin \& Binns (1988) e Annicchiarico (1992) foi verificada somente quando as médias dos genótipos foram próximas da média das testemunhas (ponto de referência). Em tais situações, um número maior de ambientes avaliados pode ser necessário para melhor definir a adaptabilidade dos referidos genótipos. Apesar da pouca discordância, o 
método de Eberhart \& Russel (1966) teve a vantagem de indicar genótipos com adaptação a ambientes específicos.

\section{CONCLUSÕES}

Para os Estados do Rio Grande de Sul e Paraná, os híbridos Agrobel 959 e Helio 360 e a variedade BRSGira 02 são ideais, por apresentar bons desempenhos em rendimento de grãos, adaptabilidade geral e boa previsibilidade. Para rendimento de óleo, essas características são encontradas nos híbridos Agrobel 959 e EXP 1441 e nas variedades BRSGira 01, BRSGira 02 e BRSGira 03.

\section{AGRADECIMENTOS}

Aos pesquisadores e instituições que avaliaram os ensaios de genótipos de girassol, cujos dados experimentais foram necessários para a elaboração desse trabalho.

\section{REFERÊNCIAS BIBLIOGRÁFICAS}

AGÊNCIA NACIONAL DO PETRÓLEO. O biodiesel

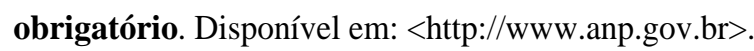
Acesso em: 9 jul. 2008.

ANNICCHIARICO, P. Cultivar adaptation and recommendation from alfalfa trials in Northern Italy. Journal of Genetics and Plant Breeding, Bergamo, v.46, n.3, p.269-278, Sept. 1992

CARVALHO, C.G.P. de; ARIAS, C.A.A.; TOLEDO, J.F.F.; ALMEIDA, L.A. de; KIIHL, R.A.S.; OLIVEIRA, M.F. Adaptability and stability study of soybean lines developed for high yield in Paraná State using four methodologies. Crop Breeding and Applied

Biotechnology, Londrina, v.2, n.2, p.247-256, jun. 2002.

COMISSÃO NACIONAL DE ABASTECIMENTO. Balança comercial do agronegócio. Disponível em: $<\mathrm{http}: / /$ www.conab.gov.br/conabweb/download/indicadores/ 0206_balanca importacao.xls>. Acesso em: 13 jul. 2007
CRUZ, C.D. Programa Genes: versão Windows: aplicativo computacional em genética e estatística. Viçosa, MG: UFV, 2001. 648p.

EBERHART, S.A.; RUSSELL, W.A. Stability parameters for comparing varieties. Crop Science, Madison, v.6, n.1, p.36-40, Jan. 1966.

KNOTHE, G. Dependence of biodiesel fuel properties on the structure of fatty acid alkyl esters. Fuel Processing Technology, Amsterdam, v.86, n.10, p.1059-1070, June 2005.

LIN, C.S.; BINNS, M.R. A superiority measure of cultivar performance for cultivar x location data. Canadian Journal of Plant Science, Ottawa, v.68, n.1, p.193-198, Jan. 1988

MACHADO, D. Biodiesel de girassol já movimenta motores. Disponível em: <http://www.biodieselbr.com// inoticias/em-foco/biodiesel-girassol-movimenta-motorest 13-06-08.htny >. Acesso em: 17 jun. 2008.

PIMENTEL GOMES, F. Curso de estatística

experimental. São Paulo: Nobel, 1985. 468p.

PORTO, W.S.; CARVALHO, C.G.P.; PINTO, R.J.B. Adaptabilidade e estabilidade como critérios para seleção de genótipos de girassol. Pesquisa Agropecuária Brasileira, Brasília, v.42, n.4, p.491-499, abr. 2007.

PORTO, W.S.; CARVALHO, C.G.P.; PINTO, R.J.B.; OLIVEIRA, M.F.; OLIVEIRA, A.C.B. de. Evaluation of sunflower cultivar for central Brazil. Scientia Agricola, Piracicaba, v.65, n.2, p.139-144, mar./abr. 2008. 